\title{
Predictive Role of Duration of Treatment, Social Anxiety in Self-Efficacy to Resist Alcohol among Persons with Alcohol Use Disorder in Ghana
}

\author{
Marie Pearl Agordzo ${ }^{1}$, Joseph Kwarteng Ofosuhene-Mensah ${ }^{1}$, Kofi Krafona ${ }^{1}$ and \\ George Ekem-Ferguson ${ }^{2 *}$
}

${ }^{1}$ Department of Education and Psychology, University of Cape Coast, Ghana

${ }^{2}$ Department of Psychiatry, Korle Bu Teaching Hospital, Ghana

*Corresponding author: George Ekem-Ferguson, Department of Psychiatry, Korle Bu Teaching Hospital, Accra-Ghana, Ghana, Tel: +233246130316

\begin{abstract}
Background: Self-efficacy to resist alcohol use is necessary to prevent relapse after treatment. However, the duration of patients stay in treatment and social anxiety are crucial in treatment outcomes of patients but its predictive role in selfefficacy to resist alcohol in the Ghanaian context is yet to be known.

Methods: Sixty participants obtained through purposive sampling participated in the study. These participants were patients with an established diagnosis for alcohol use disorder within the three main public psychiatric institutions and a specialized alcohol rehabilitation clinic in Ghana. Participants' demographic information was analysed using frequencies while multiple linear regression was used to test the hypothetical idea of the study.

Results: $55 \%$ of the sample had severe social anxiety, $53 \%$ had been in treatment for more than three months and $60 \%$ of participants in the study had low self-efficacy to resist alcohol. Also, social anxiety and duration of treatment significantly predicted self-efficacy to resist alcohol. $15 \%$ of the variation in self-efficacy to resist alcohol was explained by participants' social anxiety and duration in treatment.

Conclusions: Social anxiety and duration of treatment are the key influence of self-efficacy to resist alcohol among inpatients receiving treatment for alcohol use disorder in Ghana.
\end{abstract}

\section{Keywords}

Alcohol use disorder, Social anxiety, Self-efficacy to resist alcohol

\section{Introduction}

Alcohol is a legal psychoactive substance that has provided both benefits and costs to its consumers. Researchers and clinicians have both found alcohol to be associated with physical and psychological health problems including alcohol use disorder [1,2]. Alcohol use disorder is defined by Kranzler and Soyka [3] as a problematic pattern of compulsive and uncontrolled alcohol use associated with clinically significant impairment or distress to the individual. The WHO [1] report intimated that alcohol use disorders contributed to 1 out of every 20 deaths in 2016 and more than $5 \%$ of the global disease burden. However, there are different treatment modules purposely designed for persons with alcohol use disorders including mutual aid groups such as Alcohol Anonymous (AA) and other specialized treatment modules or both [4]. This notwithstanding, alcohol use disorders can be described to be on a spectrum with those at the severe end of the spectrum (dependence) finding it difficult to benefit from help geared towards quitting the use of the substance [5].

In Ghana, alcohol use dates back to the pre-colonial era [6]. Before the arrival of the colonial masters, akpeteshie, a traditional locally produced alcoholic beverage was consumed in Ghana. According to Isidore [7] akpeteshie, a local alcohol beverage in Ghana, has a historical significance for the people of Ghana because

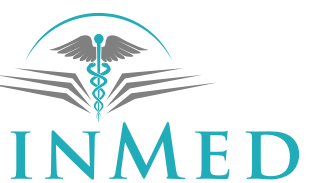

INTERNATIONAL LIBRARY

Citation: Agordzo MP, Ofosuhene-Mensah JK, Krafona K, Ekem-Ferguson G (2022) Predictive Role of Duration of Treatment, Social Anxiety in Self-Efficacy to Resist Alcohol among Persons with Alcohol Use Disorder in Ghana. Int Arch Subst Abuse Rehabil 4:012. doi.org/10.23937/2690-263X/1710012 Accepted: February 05, 2021: Published: February 07, 2021

Copyright: (C) 2022 Agordzo MP, et al. This is an open-access article distributed under the terms of the Creative Commons Attribution License, which permits unrestricted use, distribution, and reproduction in any medium, provided the original author and source are credited. 
as a local gin, colonial administrators barred it in an attempt to control the West African liquor trade in the early part of the last century. The brewing, sale, and consumption of the locally brewed substance was prohibited and offenders were prosecuted and jailed. Activities associated with the drink thus became an underground business and this gave rise to the name akpeteshie; which in Ga, a local dialect in Ghana means secrecy.

Alcohol use and its related problems are considered a medical and psychological challenge in Ghana. Ofori, et al., [8] have indicated that 1.2 million Ghanaians experience alcohol and drug-related problems owing to problems such as unemployment, economic hardship [9] and sense of loss, interpersonal conflicts, religiocultural factors, and treatment-based issues [10]. Even though national data on alcohol use disorders is not readily available in Ghana, statistics available from WHO [11] report that Ghanaian college students rank 3rd in Africa for alcohol use with Benin as $1^{\text {st }}$ and Botswana $2^{\text {nd }}$. Ghana also ranked $16^{\text {th }}$ in continental alcohol use.

Despite this, alcohol use disorders are a misconstrued condition in Ghana as persons with the condition are perceived to have moral defects [12]. This is deepened by the significant influence of religion in most Ghanaian societies, which tends to shape public perception of issues including substance use disorders, and consequently, spiritual explanations are offered by persons with alcohol use disorders for the condition [13]. The underlying cause of the disorder such as depression and anxiety [14] are however often overlooked.

However, in instances where substance use disorders are conceptualized as a health concern, they are tied to mental illness [12]. Consequently, there is some iota of stigmatization and discrimination as in the case of most mental illnesses in Ghana $[15,16]$, and this development is also likely to influence people's willingness to seek treatment for their condition. It is further possible that the stigma attached to alcohol use disorders will likely drive people into social anxiety. Social anxiety is a type of anxiety disorder described by the Diagnostic and Statistical Manual for Mental Disorders $V$ to be marked with fear or anxiety about one or more social situations in which the individual is exposed to possible scrutiny by others [17]. The individual with social anxiety is often anxious about the perception others have of him and thus is likely to experience signs or symptoms of anxiety when in social situations.

Literature has acknowledged the comorbidity of alcohol use disorder and social anxiety [18-22]. A report by the World Health Organisation details that persons with alcohol use disorders who have comorbid anxiety disorders are likely to relapse during the first three months of treatment while Herd \& Borland [23] indicated relapse rates ranging from $35 \%$ to $95 \%$ three months after treatment of persons with alcohol use disorder. It therefore sufficesto assert that social anxiety threatens the success of professional help offered to persons with alcohol use disorder.

Bandura [24] explains the use or consumption of alcohol via the social cognitive theory. According to this theory, people's use of alcohol can be partly explained by outcome expectancies, thus, the consequences derived from the use of the substance. This is the judgement of the effects of alcohol for the individual, particularly the reinforcement derived from the use of the substance. Moreso, literaturehas provided empirical evidence of outcome expectancies as a contributing factor in alcohol use $[25,26]$ across different contexts.

Positive and negative reinforcement are the outcome expectancies markedly associated with both alcohol use and misuse [27]. Positive reinforcement describes the pleasant feelings and effects derived from the use of the substance while negative reinforcement refers to the use of alcohol to obtain relief from negative affective states such as depression and anxiety. Jester, et al., [28] asserted that negative reinforcement unlike positive reinforcement is a predictor of subsequent drinking-related problems and alcohol use disorder. Consequently, negative affects such as depression, stress, anxiety or social anxiety disorders are more likely to be found among persons with alcohol use disorder.

Alcohol use disorder is a public health concern and treatment is imperative and often geared toward sobriety of the individual with little chance of relapse. Ultimately when an individual is able to effectively achieve this feat, it becomes an immense accomplishment for that individual, the family, society, and the nation at large. It is, therefore, necessary for persons receiving treatment for alcohol use disorders to acquire the strength, will, and self-efficacy to resist alcohol. However, little is known about the self-efficacy to resist alcohol among inpatients receiving treatment for alcohol use disorders in Ghana.

Self-efficacy to resist alcohol is a concept describing the judgement of one's ability toavoid drinking heavily and one's belief in self to modify alcohol use or abstainfrom alcohol use [29]. This research seeks to assess the predictive role of social anxiety and duration of treatment in self-efficacy to resist alcohol in persons with alcohol use disorder in Ghana.

\section{Materials and Methods}

\section{Data source}

Data was collected from three psychiatric institutions and one rehabilitation facility in Ghana, thus Ankaful Psychiatric Hospital, Accra Psychiatric Hospital, Pantang Hospital, and House of Saint Francis Rehabilitation Clinic in Ghana. 


\section{Design and setting}

The study employed a correlational design and used census for the inclusion of all three main public psychiatric hospitals in Ghana while employing purposive sampling to recruit the rehabilitation centre as part of the study as the centre was a facility solely devoted to the treatment of persons with alcohol use disorder. The three mental hospitals are all located in the southern part of the country. Two of these hospitals thus Accra Psychiatric Hospital and Pantang Hospital are located in the national capital, Accra, while Ankaful Hospital is located in Cape Coast. All these hospitals offer inpatient admissions to persons with alcohol use disorder. The Accra Psychiatric Hospital was the first mental hospital to be established in Ghana in 1904 as the Lunatic Asylum. The Ankaful Psychiatric Hospital now Ankaful Hospital was established next in 1965 while the Pantang Hospital was the last to be established in 1975. House of Saint Francis Rehabilitation Clinic was also established in 2012 and it admits 25 persons at a time for treatment of alcohol use disorder.

\section{Study participants}

The study was made up of sixty (60) inpatients receiving treatments across four institutions in Ghana. Purposive sampling was adopted to obtain study participants. This was to exempt persons suffering from alcohol-induced psychosis and persons with severe medical conditions causing severe physiological or psychological impairment from the study. All participants had been clinically diagnosed with alcohol use disorder and been in treatment for at least two weeks.

\section{Outcome measure}

The outcome variable measured in this study was the participant's perceived self-efficacy to resist alcohol after at least one week in treatment. Self-efficacy to resist alcohol was measured with the Alcohol Abstinence SelfEfficacy Scale (AASES). This is a Likert scale categorised as $1=$ Not Confident at all, 2 = Slightly Confident, $3=$ Moderately Confident, $4=$ Very Confident, $5=$ Extremely Confident to determine one's perceived self-efficacy to resist alcohol.

\section{Exposure variable}

Considering the formulated hypotheses for the study, duration of treatment and social anxiety were the exposure variables in the study. Participants' duration of treatment was measured in the number of weeks they had spent in treatment. Participants were also to self-report their feeling of social anxiety on the social interaction anxiety scale (SIAS). This was categorised as $1=$ Not at all, $2=$ Slightly, $3=$ Moderately, $4=$ Very, $5=$ Extremely.

\section{Data analysis}

Frequencies were used to analysethe demographic characteristics of participants in the study. To test for the hypothetical idea of the study, data were analysed using multiple linear regression. This statistical tool allows for prediction to be made from the two exposure variables of interest on the outcome variable [30]. This tool was also used to test the association between variables. Multiple regression analysis helps a researcher to explain the extent of variation of the independent variables in the dependent variable in a study.

\section{Ethics}

Ethical approval was sought from the University of Cape Coast Ethical Review Board and ethical procedures were strictly observed regarding participation in research activities. In addition to this, approval was sought from the head of participating institutions involved in the study. Informed consent was also obtained from individual participants before data collection while anonymity was ensured with no marker to indicate participants' identity.

\section{Results}

\section{Participants characteristics}

The study involved 60 inpatients receiving treatment for alcohol use disorder from three psychiatric institutions and one rehabilitation facility in Ghana. There were 56 (93.3\%) males and 4 (6.7\%) females with most of them between the ages of 31-40 years. Of the 60 participants in the study, majority of them were single (70\%) and Christians (91.7\%). Overall, most of the participants $(53.3 \%)$ had been in treatment for more than 13 weeks (more than 3 months).

The results also showed that 33 participants out of the $60(55 \%)$ experienced severe social anxiety while $14(23.3 \%)$ were in the normal range of social anxiety and $13(21.7 \%)$ experienced moderate social anxiety. Furthermore, more than half the number of participants in the study (53.3\%) had been in treatment for more than 3 months. However, 36 participants $(60 \%)$ reported low self-efficacy to resist alcohol while 24 participants $(40 \%)$ also indicated having high self-efficacy to resist alcohol (Table 1).

Multiple linear regression was calculated to predict perceived self-efficacy to resist alcohol based on social anxiety and duration of treatment. The results of the regression indicated the two predictors explained $12.5 \%$ of the variance $\left(R^{2}=0.16, F(2,57)=5.2, p<0.1\right)$. It was found that social anxiety significantly predicted self-efficacy to resist alcohol $(\beta=-0.28, p<0.05)$ as did duration of treatment at $(\beta=0.31, p<0.05)$. Duration of treatment carried a significant positive regression weight, thus longer duration in treatment was expected to produce higher self-efficacy to resist alcohol while social anxiety on the other hand recorded a significant negative regression weight which meant those with higher social anxiety scores were expected to have 
lower self-efficacy to resist alcohol after controlling for other variables in the model (Table 2 ).

\section{Discussion}

Self-efficacy to resist alcohol was relatively low considering the percentage of persons with low selfefficacy to resist alcohol (60\%) to those who had a high self-efficacy to resist alcohol. According Kushner, et al., [31] treating one (alcohol use disorder) of comorbid conditions (social anxiety and alcohol use disorder)

Table 1: Sample characteristics $(N=60)$.

\begin{tabular}{|c|c|c|}
\hline Demographic & $N$ & $\%$ \\
\hline \multicolumn{3}{|l|}{ Sex } \\
\hline Male & 56 & 93.3 \\
\hline Female & 4 & 6.7 \\
\hline \multicolumn{3}{|l|}{ Age } \\
\hline $18-30$ years & 23 & 38.3 \\
\hline $31-40$ years & 24 & 40.0 \\
\hline $41-50$ years & 7 & 11.7 \\
\hline 51 years and above & 6 & 10.0 \\
\hline \multicolumn{3}{|l|}{ Marital Status } \\
\hline Single & 42 & 70.0 \\
\hline Married & 12 & 20.0 \\
\hline Divorced & 2 & 3.3 \\
\hline Separated & 4 & 6.7 \\
\hline \multicolumn{3}{|l|}{ Duration in Treatment } \\
\hline 2-4 weeks & 4 & 6.7 \\
\hline 5-6 weeks & 5 & 8.3 \\
\hline $7-8$ weeks & 2 & 3.3 \\
\hline 9-10 weeks & 2 & 3.3 \\
\hline $11-12$ weeks & 15 & 25.0 \\
\hline 13 weeks and above & 32 & 53.3 \\
\hline \multicolumn{3}{|l|}{ Religion } \\
\hline Christian & 55 & 91.7 \\
\hline Muslim & 4 & 6.7 \\
\hline Traditional & 1 & 1.7 \\
\hline \multicolumn{3}{|l|}{ Social anxiety } \\
\hline Normal & 14 & 23.3 \\
\hline Moderate & 13 & 21.7 \\
\hline Severe & 33 & 55.0 \\
\hline \multicolumn{3}{|c|}{ Self-Efficacy to resist alcohol } \\
\hline Low & 36 & 60.0 \\
\hline High & 24 & 40.0 \\
\hline
\end{tabular}

is not an effective regimen. This is asserted because anxiety disorder has been described to typically and often occur prior to the onset of alcohol use disorder [32]. Thus, offering treatment for solely alcohol use disorder may leave the individual vulnerable to relapse before the completion of treatment $[31,33]$. Treatment for alcohol use disorder in Ghana usually is designed in a manner that the presence of comorbid psychopathology may often not be a primary focus even though some efficacious methods and treatments are provided.

In another study by Kushner, et al., [34] it was found that the risk for developing an alcohol use disorder tripled with persons with an anxiety diagnosis. This is supported by high levels of social anxiety found in persons with alcohol use disorder in Ghana [18]. Schomerus, et al., [35] described the person with alcohol use disorder as a deviant, thus one deviating from the acceptable norms of his/her given context. This description is no different from the conceptualization of alcohol use disorders in the Ghanaian context. Derogatory labels in the native languages such as 'dantorlor, korinsani and ahanola' all meaning drunkard assigned to such persons in the local Ghanaian communities, this is due to their condition which is believed deviates from acceptable Ghanaian norms. However, researchers have asserted that stigmatizing these persons could eventually be a self-fulfilling prophecy that could contribute to their outcomes [35]. This could probably account for the low self-efficacy to resist alcohol among participants in this study. Literature has largely found that comorbidity in alcohol use disorder is further associated with worse alcohol treatment outcomes, relapse, and readmissions [36,37].

The present study also revealed that social anxiety and duration of treatment significantly predicted selfefficacy to resist alcohol. The validity of the model could be explained by studies such as Zimmermann, et al., [38] who reported that social anxiety is a primary cause of alcohol use disorder. This can be described as a mechanism underlying the use of alcohol to selfmedicate and consequently reduce tension associated with anxiety. Another research by Kessler, et al., [39] in a community survey also reported a similar trend where people with social anxiety disclosed that they have consciously used alcohol to manage their anxieties. This points to the fact that alcohol's tranquilising effects have proven to be an effective anxiolytic for its users. It is thus justifiable to assert that one's anxiety is present,

Table 2: Association betweenperceived self-efficacy to resist alcohol, social anxiety, and duration of treatment.

\begin{tabular}{|l|l|l|l|l|l|l|}
\hline \multicolumn{1}{|c|}{ Model } & B & SEM & B & t & Sig. \\
\hline \multirow{2}{*}{1} & (Constant) & 64.693 & 10.315 & & 6.272 & 0.000 \\
\cline { 2 - 7 } & Social anxiety & -0.477 & 0.208 & -0.282 & -2.298 & 0.025 \\
\cline { 2 - 7 } & Treatment duration & 3.127 & 1.234 & 0.311 & 2.534 & 0.014 \\
\hline
\end{tabular}

a. Dependent Variable: Self-efficacy to resist alcohol $R=0.393, R^{2}=0.155 ; F=5.208, P=0.008$ 
alcohol use becomes highly probable. It is thus not surprising to find a high level of social anxiety among the sample and consequently a low self-efficacy to resist alcohol.

Duration of treatment as observed in this study significantly contributed to the regression model produced in this present research. This supports the dose-effect model of treatment. This model is predicated on the medical assertion that there is a positive association between the dose (number of sessions) clients receive and the treatment outcomes [40] as opposed to the good-enough level model of treatment. The good-enough level model is based on the premise that patients can be considered as asynchronous, differing from one another. Thus, they will respond to treatment at different rates with longer duration been associated with less rapid rates of individual change [41]. Both models have been applied in assessing how much therapy is enough for patients and have both sought to answer 'what should be the optimal duration of therapy?'.

Despite suggesting that the longer the duration of treatment the better the treatment outcome the doseeffect model also acknowledges that, like marginal utility, beyond several doses, the essence of additional doses (therapy) decreases [42]. Findings from this study lend support to experts' calls and recommendations which have argued that alcohol use disorders should be considered as chronic conditions. The implication is that treatment is expected to occur over a much longer duration [43]. Thus, an arguably longer duration of time needs to be spent in rendering treatment services to persons with alcohol use disorder. Despite this assertion, Barkham, et al., [41] found otherwise by arguing that a longer duration of treatment was associated with less rates of individual-level change. To reiterate, inpatients at least for the sample of participants in this study reported a high prevalence of social anxiety despite being in treatment for more than 3 months.

Reasoning from the above, it is imperative and recommended to consider the treatment options made by Kushner, et al., [32] in treating persons with alcohol use disorder. They suggested three approaches that clinicians could consider to provide treatment for their clients. These include the (i) Serial or sequential approach where alcohol use disorder and social anxiety are treated as comorbid disorders but considered one at an instance, (ii) Parallel approach typically involving offering distinct treatment for each condition separately or (iii) Integrated approach that requires that one treatment that can tackle both comorbid disorders be considered for treatment.

Although research has provided different perspectives on which duration of treatment is more efficacious in the treatment of alcohol use disorders, these treatment options need to be critically tested and integrated into treating persons with alcohol use disorder in Ghana. This is been suggested because the duration of treatment proved to be a significant predictor of participants' perceived self-efficacy to resist alcohol. Against this background, it is necessary for clinicians in the area of alcohol use disorder treatment to consider the presence of social anxiety and the duration of clients' treatment as significant indicators of self-efficacy to resist alcohol. This suggestion is further conveyed because studies such as Greenfield, et al. [44] reported a significant relationship between selfefficacy expectancies and other variables including the likelihood of drinking among inpatients. In another study by Vielva \& Iraurgi [45] it was found that participants who had high confidence to resist drinking were more likely to keep abstinent for six months. Also, findings from Merikangas, et al., [46] and Morris, et al. [47] have suggested that alcohol use disorder and social anxiety do not merely coexist but interact. The interaction could mean treatment of a single disorder in the comorbidity is likely to impair the success of that treatment.

\section{Conclusion}

Persons with alcohol use disorders in Ghana had disturbingly low self-efficacy to resist alcohol coupled with high social anxiety despite receiving amajority treatment for a period more than three months. Interestingly, comorbidity and combined treatment are neither recognized nor given the needed attention [48]. However, WHO [49] declared comorbidity in alcohol use disorder as a threat and major challenge in public health and clinical practice and recommends an integrated approach to treatment. It is recommended that treatment approaches designed for alcohol use disorders in Ghana heed to the calls of time. Persons with alcohol use disorders need more than treatment directed solely to their alcohol use disorder but one that can tackle other comorbidities including social anxiety while offering a considerably long enough duration of treatment.

\section{Limitations}

The generalization of this study is limited by the sample size and the purposive selection of participants in the study. Participants in the study have multiple substance use problems which may affect their selfefficacy to resist only alcohol. The instruments used were also self-reported measures hence susceptible to socially desirable responses from participants. In addition to these, treatment received by the participants in the study may vary by institution.

\section{Acknowledgement}

The authors express profound gratitude to the management and staff of the Ankaful Hospital, Pantang Mental Hospital and Accra Psychiatric Hospital as well as House of Saint Francis Rehab Clinic. The authors are also thankful to all participants who partook in the 
study and provided responses necessary for this study to be carried out.

\section{Contributors}

MariePearl Agordzo conceptualized and drafted the manuscript. Joseph Kwarteng Ofosuhene Mensah analysed the data and George Ekem-Ferguson revised the draft manuscript. Kofi Krafona provided intellectual poof reading of the final manuscript.

\section{Declaration of Interest Statement}

The authors declare there are no competing interest.

\section{References}

1. World Health Organisation (2018) Global status report on alcohol and health.

2. Rehm J (2011) The Risks Associated With Alcohol Use and Alcoholism. Alcohol Res Health 34: 135-143.

3. Kranzler HR, Soyka M (2018) Diagnosis and Pharmacotherapy of Alcohol Use Disorder: A Review. JAMA 320: 815-824.

4. National Institute for Health and Clinical Excellence (2010) Alcohol Use Disorders: Diagnosis and Clinical Management of Alcohol-Related Physical Complications. Royal College of Physicians (UK).

5. Day E, Copello A, Hull M (2015) Assessment and management of alcohol use disorders. BMJ 350.

6. Akyeampong E (1996) What's in a Drink? Class Struggle, Popular Culture and the Politics of Akpeteshie (Local Gin) in Ghana, 1930-1967*. The Journal of African History 37: 215-236.

7. Isidore SO (2001) Drug and Alcohol Consumption by out of school Nigerian Adolescents. African Journal of Drug and Alcohol Studies 1: 99.

8. Ofori -Atta A, Read UM, Lund C (2010) A situation analysis of mental health services and legislation in Ghana: Challenges for transformation: original article. Afr J Psychiatry 13: 99-108.

9. Brown-Acquaye HA (2001) Drug abuse among the youth in Ghana. African Journal of Educational Studies in Mathematics and Sciences 1.

10. Appiah R, Danquah SA, Nyarko K, Ofori-Atta AL, Aziato L (2017) Precipitants of Substance Abuse Relapse in Ghana: A Qualitative Exploration. Journal of Drug Issues 47: 104-115.

11. World Health Organization (2011) Global status report on alcohol and health. WHO.

12. Bird L (2019) Domestic drug consumption in Ghana. An underreported Phenomenon. Global initiative Against Transnational Organised Crime.

13. Agoabasa FA (2012) Alcoholism among women and its impact on the socio-economic development of Ghana: A case study of Sandema [Unpublished Thesis, Ashesi University].

14. Oppong Asante K, Kugbey N (2019) Alcohol use by schoolgoing adolescents in Ghana: Prevalence and correlates. Mental Health \& Prevention 13: 75-81.

15. Barke A, Nyarko S, Klecha D (2011) The stigma of mental illness in Southern Ghana: Attitudes of the urban population and patients' views. Soc Psychiatry Psychiatr Epidemiol 46: 1191-1202.
16. Dako-Gyeke M, Asumang ES (2013) Stigmatization and Discrimination Experiences of Persons with Mental Illness: Insights from a Qualitative Study in Southern Ghana. Social Work \& Society 11 Article 1.

17. American Psychiatric Association (2013) Diagnostic and statistical manual of mental disorders (DSM-5). American Psychiatric Pub.

18. Agordzo M, Ofosuhene-Mensah JK, krafona K, EkemFerguson G (2021) Social Anxiety and Self-Compassion in Persons with Alcohol Use Disorders in Ghana. Research and Scientific Innovation Society (RSIS International) 5: 563-568.

19. Clark DB, Sayette MA (1993) Anxiety and the Development of Alcoholism. The American Journal on Addictions 2: 5976.

20. Kushner MG, Abrams K, Borchardt C (2000) The relationship between anxiety disorders and alcohol use disorders: A review of major perspectives and findings. Clin Psychol Rev 20: 149-171.

21. Randall CL (2000) Alcoholism and social anxiety disorder. Annual meeting of the Research Society on Alcoholosim, Denver, CO.

22. Schellekens AFA, Jong CAJ, de Buitelaar JK, Verkes RJ (2015) Co-morbid anxiety disorders predict early relapse after inpatient alcohol treatment. Eur Psychiatry 30: 128136.

23. Herd N, Borland R (2009) The natural history of quitting smoking: Findings from the International Tobacco Control (ITC) Four Country Survey. Addiction (Abingdon, England) 104: 2075-2087.

24. Bandura A (1977) Self-efficacy: Toward a unifying theory of behavioral change. Psychological Review 84: 191-215.

25. Borjesson WI, Dunn ME (2001) Alcohol expectancies of women and men in relation to alcohol use and perceptions of the effects of alcohol on the opposite sex. Addict Behav 26: 707-719.

26. Young RM, Connor JP, Ricciardelli LA, Saunders JB (2006) The role of alcohol expectancy and drinking refusal self-efficacy beliefs in university student drinking. Alcohol Alcohol (Oxford, Oxfordshire) 41: 70-75.

27. Kuntsche E, Knibbe R, Gmel G, Engels R (2005) Why do young people drink? A review of drinking motives. Clinical Psychology Review 25: 841-861.

28. Jester JM, Steinberg DB, Heitzeg MM, Zucker RA (2015) Coping Expectancies, Not Enhancement Expectancies, Mediate Trauma Experience Effects on Problem Alcohol Use: A Prospective Study From Early Childhood to Adolescence. Journal of Studies on Alcohol and Drugs 76: 781-789.

29. Di Clemente CC, Fairhurst SK, Piotrowski NA (1995) Self Efficacy and Addictive Behaviours. In Self-Efficacy, adaptation, and adjustment: Theory, research and application, 109-141. Plenum.

30. Uyanık GK, Güler N (2013) A Study on Multiple Linear Regression Analysis. Procedia - Social and Behavioral Sciences 106: 234-240.

31. Kushner MG, Abrams K, Thuras $P$, Hanson KL, Brekke M, et al. (2005) Follow-up Study of Anxiety Disorder and Alcohol Dependence in Comorbid Alcoholism Treatment Patients. Alcoholism: Clinical and Experimental Research 29: 1432-1443.

32. Kushner MG, Frye B, Donahue C, Book SW, Randall CL 
(2007) Which to treat first: Comorbid anxiety or alcoho disorder? Therapies that target just one problem are insufficient for patients who have both. Current Psychiatry 6: $55-62$.

33. Randall CL, Thomas S, Thevos AK (2001) Concurrent Alcoholism and Social Anxiety Disorder: A First Step Toward Developing Effective Treatments. Alcoholism: Clinical and Experimental Research 25: 210-220.

34. Kushner MG, Sher KJ, Beitman BD (1990) The relation between alcohol problems and the anxiety disorders. Am J Psychiatry 147: 685-695.

35. Schomerus G, Holzinger A, Matschinger $H$, Lucht $M$, Angermeyer MC (2010) [Public attitudes towards alcohol dependence]. Psychiatr Prax 37: 111-118.

36. Tómasson K, Vaglum $P$ (1997) The 2-year course following detoxification treatment of substance abuse: The possible influence of psychiatric comorbidity. Eur Arch Psychiatry Clin Neurosci 247: 320-327.

37. Tómasson K, Vaglum $P$ (1998) The role of psychiatric comorbidity in the prediction of readmission for detoxification. Compr Psychiatry 39: 129-136.

38. Zimmermann $P$, Wittchen $H U$, Höfler $M$, Pfister $H$, Kessler RC, et al. (2003) Primary anxiety disorders and the development of subsequent alcohol use disorders: A 4-year community study of adolescents and young adults. Psychological Medicine 33: 1211-1222.

39. Kessler RC, Berglund P, Demler O, Jin R, Merikangas KR, et al. (2005) Lifetime prevalence and age-of-onset distributions of DSM-IV disorders in the National Comorbidity Survey Replication. Archives of General Psychiatry 62: 593-602.

40. Schmidt LK, Bojesen AB, Nielsen AS, Andersen K (2018) Duration of therapy - Does it matter?: A systematic review and meta-regression of the duration of psychosocial treatments for alcohol use disorder. Journal of Substance Abuse Treatment 84: 57-67.
41. Barkham M, Connell J, Stiles WB, Miles JNV, Margison F, et al. (2006) Dose-effect relations and responsive regulation of treatment duration: The good enough level. J Consult Clin Psychol 74: 160-167.

42. Kopta SM (2003) The dose-effect relationship in psychotherapy: A defining achievement for Dr. Kenneth Howard. Journal of Clinical Psychology 59: 727-733.

43. McKay JR, Hiller-Sturmhöfel S (2011) Treating Alcoholism as a Chronic Disease. Alcohol Res Health 33: 356-370.

44. Greenfield SF, Hufford MR, Vagge LM, Muenz LR, Costello ME, et al. (2000) The relationship of self-efficacy expectancies to relapse among alcohol dependent men and women: A prospective study. Journal of Studies on Alcohol 61: 345-351.

45. Vielva I, Iraurgi I (2001) Cognitive and behavioural factors as predictors of abstinence following treatment for alcohol dependence. Addiction (Abingdon, England) 96: 297-303.

46. Merikangas KR, Stevens DE, Fenton B, Stolar M, O'malley S, et al. (1998) Co-morbidity and familial aggregation of alcoholism and anxiety disorders. Psychological Medicine 28: 773-788.

47. Morris EP, Stewart SH, Ham LS (2005) The relationship between social anxiety disorder and alcohol use disorders: A critical review. Clin Psychol Rev 25: 734-760.

48. Riper H, Andersson G, Hunter SB, de Wit J, Berking M, et al. (2014) Treatment of comorbid alcohol use disorders and depression with cognitive-behavioural therapy and motivational interviewing: A meta-analysis. Addiction 109: 394-406.

49. World Health Organization. Regional Office for Europe (2019) Harmful use of alcohol, alcohol dependence and mental health conditions: A review of the evidence for their association and integrated treatment approaches (WHO/EURO:2019-3571-43330-60791). World Health Organization. Regional Office for Europe. 